\title{
GESTÃO DO USO DAS TECNOLOGIAS DIGITAIS NA EJA: ANÁLISE DOS ANAIS DO EVENTO INTERNACIONAL DO ALFAEEJA
}

\author{
Maria Conceição Alves Ferreira (UNEB)* \\ Naiara Serafim Santos Mota (MPEJA)** \\ Bento Duarte da Silva (UMINHO)***
}

\section{RESUMO}

Este estudo foi realizado com base nos Anais do Encontro Internacional de Alfabetização e Educação de Jovens e Adultos (ALFAEEJA), organizado pelo MPEJA/UNEB, desde 2014. Procuramos analisar como as tecnologias digitais estão sendo inseridas na EJA, no âmbito das publicações nos Anais do ALFAEEJA de 2014 a 2018. 0 objetivo maior foi o seguinte: investigar a inserção das tecnologias digitais na EJA, destacando os processos inovadores. Foi uma investigação qualitativa, com o dispositivo estratégico da pesquisa bibliográfica e leitura reflexiva dos Anais de 2014 a 2018. Os resultados apresentados: já há inserção das tecnologias digitais na EJA que superam o viés meramente instrumental; há proposições de formação autônoma que inovam o ambiente tecnológico; é preciso superar os preconceitos para fortalecer o contexto do digital na Educação de Jovens e Adultos.

Palavras-chave: Educação de Jovens e Adultos. Tecnologias digitais. Processo de ensino-aprendizagem. ALFAEEJA.

\begin{abstract}
MANAGEMENT OF THE USE OF DIGITAL TECHNOLOGIES IN ADULT AND YOUTH EDUCATION: ANALYSIS OF THE ANNALS OF THE INTERNATIONAL EVENT OF ALFAEEJA

This study was carried out on the basis of the proceedings of the international meeting of adult and youth literacy and education (ALFAEEJA), organized by the MPEJA/UNEB, from 2014. We seek to examine how digital technologies are being inserted into the EJA, under the publications in the annals of ALFAEEJA from 2014 to 2018 . The main objective was the following: investigate
\end{abstract}

* Doutora em Educação pela Universidade do Rio Grande do Norte (UFRN). Pós-Doutorado pela Universidade do Minho - UMinho/Portugal, professora Adjunta do Departamento de Educação do Campus I, da UNEB. E-mail: consinha@terra.com.br.

** Professora da Rede estadual de ensino da Bahia. Mestranda pelo Programa de Pós-Graduação em Educação de Jovens e Adultos - MPEJA. E-mail: naiaramota_nw@hotmail.com

*** Doutor em Educação na especialidade de Tecnologia Educativa e professor do Instituto de Educação e Psicologia da Universidade de UMINHO, PT. E-mail: bento@ie.uminho.pt 
the integration of digital technologies in the EJA, highlighting the innovative processes. It was a qualitative research, with the strategic device bibliographical research and reflective reading of annals of 2014 to 2018. The results: there are already digital technologies insertion in the EJA that go beyond the merely instrumental bias; There are stand-alone training propositions that innovate the technological environment; It is necessary to overcome the prejudices to strengthen the digital context on Adult and youth education.

Keywords: Education of Young and Adult. Digital technologies. Teaching-learning process. ALPHA and EJA.

\section{RESUMEN}

\section{GESTIÓN DEL USO DE LAS TECNOLOGÍAS DIGITALES EN LA EDUCACIÓN DE JÓVENES Y ADULTOS: ANÁLISIS DE LOS ANALES DEL EVENTO INTERNACIONAL DE ALFAEEJA}

Este estudio se realizó sobre la base de las actas del encuentro internacional de adultos y alfabetización de jóvenes y educación (ALFAEEJA), organizadas por lo MPEJA/UNEB, desde 2014. Buscamos examinar como las tecnologías digitales se insertan en la EJA, debajo de las publicaciones en los Anales de ALFAEEJA de 2014 a 2018. El objetivo principal fue el siguiente: investigar la integración de las tecnologías digitales en la EJA, destacando los procesos innovadores. Fue una investigación cualitativa, investigación bibliográfica dispositivo estratégico y reflexiva lectura de los Anales de 2014 a 2018. Los resultados: ya hay inserción de tecnologías digitales en la EJA que van más allá del sesgo meramente instrumental; Hay propuestas de formación independiente que innovan el entorno tecnológico; Es necesario superar los prejuicios para fortalecer el contexto digital en la educación de adultos y jóvenes.

Palabras clave: Educación de Jóvenes y Adultos. Tecnologías digitales. Proceso de enseñanza-aprendizaje. ALFAEEJA.

\section{INTRODUÇÃO}

Neste artigo realizamos um estudo sistemático sobre as tecnologias digitais na educação de jovens e adultos a partir das publicações no site ${ }^{1}$ do Encontro Internacional de Alfabetização e Educação de Jovens e Adultos (ALFAEEJA) de 2014 a 2018. O ALFAEEJA promovido pelo Programa de PósGraduação em Educação de Jovens e Adultos (MPEJA) da Universidade Estadual da Bahia (UNEB) desde 2014, é um evento que conta com a participação de várias Instituições de Educação Superior (IES) do Brasil e do exte-

1 Fonte: https://www.alfaeejauneb.com. Acesso em out. 2019. rior, a exemplo de universidades de Portugal, da Espanha e da Inglaterra.

Entendemos que as tecnologias digitais são práticas sociais que favorecem as transformações sociais, econômicas e culturais, estas tecnologias estão provocando alterações nas relações entre o ser humano e o seu cotidiano. Neste âmbito, os sujeitos jovens e adultos utilizam essas tecnologias para se comunicar, para se divertirem e aprenderem sobre temas relacionados a projetos pessoais e a conteúdos culturais de seu interesse. Essa relação do sujeito com os artefatos digitais, em seu dia-a-dia, leva 
a pensar a educação como sendo um espaço de formação para o uso consciente e autônomo desses meios, na atualidade.

Visto isso, este estudo se propôs a responder ao seguinte: como as tecnologias digitais estão sendo inseridas na EJA, no âmbito das publicações dos Anais do ALFAEEJA 2014 a 2018? Trata-se de uma questão que necessita ser estudada a fim de averiguarmos o trabalho que vem sendo desenvolvido na educação de jovens e adultos, que inserem as tecnologias digitais como potencialidades no processo de ensino-aprendizagem. Para aprofundar o estudo da temática precisamos analisar a inserção das tecnologias digitais na EJA e verificar as contribuições inovadoras da inserção dessas tecnologias digitais para os educandos jovens e adultos.

\section{PROCEDIMENTOS METODOLÓGICOS DA INVESTIGAÇÃO}

A abordagem que norteia este estudo é a qualitativa que visa valorizar a compreensão do objeto estudado, procurando explicar o porquê das coisas, não se preocupando com resultados numéricos (SILVEIRA; CÓRDOVA 2009). Esta faz parte de questões ou focos de interesse amplo que vão se definindo à medida que o estudo se desenvolve, buscando por meio da obtenção de dados descritivos compreender os fenômenos que se apresentam na situação em estudo. É uma pesquisa emergente em vez de estritamente pré-configurada, sendo que diversos aspectos surgem durante um estudo qualitativo e as questões de pesquisa podem mudar e ser refinadas (CRESWEL, 2007).

Quanto aos objetivos, por ser um estudo realizado em área na qual há conhecimento acumulado e sistematizado, a investigação se caracteriza como sendo exploratória, pois, conforme Gil (2008, p. 27) “[...] este tipo de pesquisa é realizado especialmente quando o tema escolhido é pouco explorado e torna-se difícil sobre ele formular hipóteses precisas e operacionalizáveis".

A pesquisa tem como procedimento estratégico na coleta de dados um processo de busca sistemática, além de se caracterizar como sendo uma investigação bibliográfica, que é desenvolvida com base em material já elaborado, constituído principalmente de livros e de artigos científicos nos quais podem ser encontrados em várias fontes, desde bibliotecas físicas aos meios digitais. Conforme Severino (2007, p. 122):

A pesquisa bibliográfica é aquela que se realiza a partir do registro disponível, decorrente de pesquisas anteriores, em documentos impressos, como livros, artigos, teses etc. Utiliza-se de dados ou de categorias teóricas já trabalhados por outros pesquisadores e devidamente registrados. Os textos tornamse fontes dos temas a serem pesquisados. 0 pesquisador trabalha a partir das contribuições dos autores dos estudos analíticos constantes dos textos.

Nossas fontes de investigação foram os textos de apresentação do site (BAHIA, 2014-2018) e os Anais do Encontro Internacional de Alfabetização e Educação de Jovens e Adultos (ALFAEEJA) de 2014 a 2018 (BAHIA, 2014-2018a). Realizamos uma revisão sistemática das publicações deste evento no intuito de investigar a inserção das tecnologias digitais na EJA. Tudo isso, porque acreditamos conforme Gil (2002) que os encontros científicos, tais como congressos, simpósios, seminários e fóruns, constituem locais privilegiados para apresentação de comunicações científicas, sendo para nós também um espaço rico em pesquisas que envolvem Tecnologias digitais e EJA.

Como resultado desse processo, foram identificadas 61 publicações que envolvem 
tecnologias digitais na EJA e que foram extraídas dos Anais do Encontro Internacional de Alfabetização e Educação de Jovens e Adultos (ALFAEEJA) de 2014 a 2018 e analisados os trabalhos considerados como destaque para a tecnologia digital em EJA.

A revisão sistemática conforme Sampaio e Mancini (2007) é uma forma de pesquisa que utiliza como fonte de dados a literatura sobre determinado tema. Neste âmbito, as etapas iniciais são muito importantes para que o pesquisador consiga ir adequando a questão investigativa da revisão tendo por base os dados encontrados sobre a temática. Sampaio e Mancini (2007) apresentam os passos de uma revisão sistemática de literatura, as quais se configuram em um conjunto rigoroso de critérios para avaliar a confiabilidade e a validade de pesquisas publicadas anteriormente.

0 primeiro passo para uma revisão sistemática de literatura foi a definição da pergunta. Se faz necessária uma pergunta ou questão bem formulada e clara. 0 segundo passo foi a busca por evidências na qual devemos identificar as bases de dados a serem consultadas; definir palavras-chave e estratégias de busca. 0 terceiro passo é a revisão e seleção dos estudos, momento em que estabelecemos critérios para a seleção dos artigos a partir da busca. 0 quarto passo é a análise da qualidade metodológica dos estudos, no qual analisamos criticamente e avaliamos todos os estudos incluídos na revisão. 0 quinto e último passo é a apresentação dos resultados que podemos expor na forma de quadro destacando as principais características dos artigos incluídos na revisão sistemática, respondendo à questão inicial do estudo.

Com base nos estudos realizados para a elaboração desse tópico, é possível refletirmos acerca da importância de entendermos e dominarmos os estudos que envolvem a pesquisa cientifica, a fim de realizarmos um trabalho com caráter cientifico, favorecendo uma melhor construção e disseminação do conhecimento.

\section{TECNOLOGIAS DIGITAIS E A EDUCAÇÃO DE JOVENS E ADULTOS NA CONTEMPORANEIDADE}

A tecnologia pode ser considerada uma extensão de algumas habilidades do ser humano, que potencializa e transforma o ambiente em que vive (LEVY, 1999). Neste sentido, o espaço escolar também precisa integrar essa nova realidade ao seu contexto.

Com base nessas reflexões, a tecnologia vem aos poucos se fazendo presente no espaço escolar, são exemplos o livro didático, TV, rádio, videocassete, DVD, gravador de vídeo, câmera de vídeo, computador (CD ROM - DVD - softwares), internet (blogs - interatividade - colaboração). Contudo, é válido ressaltar que independente da era tecnológica que falamos, os avanços sempre demoram a chegar aos espaços públicos educativos e quando chegam, na maioria das vezes faltam os conhecimentos necessários para o desenvolvimento da ação pedagógica mais consciente e reflexiva.

Para Lévy (1999, p.28), “[...] as tecnologias digitais surgiram, então, como a infraestrutura do ciberespaço, novo espaço de comunicação, de sociabilidade, de organização e de transação, mas também novo mercado da informação e do conhecimento". Sendo assim, as tecnologias digitais se configuram como sendo uma necessidade da sociedade contemporânea que se encontra cada vez mais informatizada, levando as pessoas a estarem cada dia mais conectadas através do ciberespaço. Neste âmbito, a educação tem papel fundamental, pois, é no 
espaço educacional que os sujeitos devem compreender como utilizar da melhor forma os meios digitais, visando uma formação consciente, autônoma e reflexiva.

Nesse sentido, Alves (2016, p. 589) enfatiza que;

[...] a mudança de perspectiva em relação à interação com as distintas tecnologias digitais e telemáticas nos espaços escolares exige uma implicação e um engajamento dos sujeitos, desafiando-os a ir além do lugar de meros usuários que aprendem a utilizar a tecnologia, alfabetizam-se e tornam-se letrados nas suas interfaces.

Sabemos a real necessidade das escolas integrarem as tecnologias digitais ao currículo, favorecendo a formação dos professores para atuarem em conjunto com os novos meios de informação e produção do conhecimento. Nessa lógica, entendemos que a EJA também vivencia essa era digital, pois, os sujeitos jovens e adultos são cidadãos ativos da sociedade.

Muitas pesquisas e projetos vêm sendo desenvolvidos a fim de compreender os meios mais eficazes de inserção das tecnologias digitais na educação, contudo observamos que esses estudos, em sua ampla maioria, tem como público alvo, apenas, crianças e adolescentes. A Educação de Jovens e Adultos quase nunca aparece em pesquisas que envolvem tecnologias digitais. Segundo Arroyo (2005, p.06)

A EJA sairá dessa configuração supletiva, preventiva e moralizante se mudar o olhar sobre os jovens - adultos e os ver com seu protagonismo positivo: sujeitos de direitos e sujeitos de deveres do Estado. Aí poderá se configurar como política pública, como dever de Estado. As possibilidades de reconfigurar esse direito à educação passam por aí: por avançarmos em uma visão positiva dos jovens e adultos populares, por reconhecê -los como sujeitos de direitos.
Diante do exposto, percebemos o descaso que ainda impera com a Educação de Jovens e Adultos, em nosso país. Uma educação que ao longo da história vem sendo tratada como sendo compensatória, um ensino supletivo, de reposição de estudos não realizados na idade "certa". Nesta perspectiva, Arroyo (2005) enfatiza que a EJA é um campo ainda não consolidado nas áreas de pesquisa, de políticas públicas e diretrizes educacionais, da formação de educadores e de intervenções pedagógicas. Segundo o autor, mesmo existindo na atualidade vários indicadores de uma mobilização em torno da EJA, que podem ser percebidos nas ações do Estado, das instituições, ONG's, igrejas, e de diversos seguimentos da sociedade em geral, o sistema escolar continua fechado para esses indicadores e necessita pensar e agir com o objetivo de transformar a EJA, de fato, em "[...] um campo de responsabilidade pública" (ARROYO, 2005, p. 22).

0 percurso histórico da EJA orienta a comprendermos a ausência de projetos que visem a inovação no ensino, para os sujeitos jovens e adultos. Conforme Faria (2012), a EJA ainda é vista como sendo o lugar dos menos favorecidos, que são os pertencentes, quase sempre, a grupos minoritários, como de negros, pessoas de localidades populares, trabalhadores e trabalhadoras informais e também desempregados. Neste sentido, precisamos lutar contra o preconceito, a exclusão de diferentes formas e a discriminação que sofrem esses sujeitos em vários espaços da sociedade. Urge a necessidade em lutarmos para que a EJA se torne uma política pública e tenha projetos de inovação que incluam seus educandos na sociedade da informação.

A Educação de Jovens e Adultos tem como marcos legais, além da Constituição Federal de 1988 que garante o direito à educação de 
forma universal, como um direito de todos, a Lei de Diretrizes e Bases da Educação Nacional (LDB) n. 9.394/1996, dentre outros documentos como decretos, pareceres, resoluções e portarias, conceitos e princípios que visam demarcar o lugar da EJA, no sistema educacional e influenciar políticas públicas para essa modalidade. As autoras Costa e Machado (2017, p. 57) reforçam que:

Com isso, não se quer reduzir a EJA à escolarização; ao contrário, é fundamental que se reconheça que a luta pelo direito à educação implica, além do acesso à escola, a produção do conhecimento que se dá no mundo da cultura, do trabalho e nos diversos espaços de convívio social, em que jovens e adultos seguem constituindo-se como sujeitos.

Assim, os marcos legais que normatizam a Educação de Jovens e Adultos são de extrema importância para o alcance de visibilidade, reconhecimento e políticas que a configure como sendo um campo específico do direito à educação e à formação de coletivos sociais jovens e adultos populares. Contudo, também é preciso que essa educação não seja restrita à alfabetização ou à qualificação profissional, que visem responder a demandas do mercado de trabalho, formando jovens e adultos como mão-de-obra. Defendemos um ensino que possibilite aos educandos da EJA desenvolverem plenamente suas capacidades individuais, e que como exposto na VI Conferência Internacional de Educação de Adultos (CONFINTEA), realizada no Brasil, no estado de Belém em 2009, reconheça a aprendizagem ao longo da vida.

Entendemos que formar jovens e adultos, levando em consideração suas limitações frente as transformações vertiginosas das tecnologias, não é um processo fácil, contudo acreditamos que é possível. As tecnologias digitais já fazem parte do cotidiano da maioria das pessoas, e a escola precisa se preparar conscientemente para essa nova era onde o professor não é mais o único meio de acesso às informações.

Nesse âmbito, o desafio não é apenas o de equipar as escolas, mas preparar os educadores, principalmente da EJA, para utilizarem essas tecnologias efetivamente de forma a atender os interesses dos aprendizes e da grande comunidade de ensino e aprendizagem. Neste processo, exige-se um novo perfil do professor na sala de aula, ele deve deixar de ser o centro do processo de ensino -aprendizagem e o aluno deve assumir esse espaço. 0 professor auxilia seus alunos na busca constante pelo conhecimento, sendo uma ponte entre o aluno e a aprendizagem. Conforme Alves (2016, p. 577):

Construir um sentido diferenciado para as tecnologias digitais e da web nos espaços escolares requer uma mudança de papel dos professores e dos alunos, permitindo que esses sujeitos do processo de ensinar e aprender sejam atores e autores das suas trajetórias de aprendizagem.

0 professor da contemporaneidade precisa usar as tecnologias disponíveis a fim de proporcionar um ensino de melhor qualidade, sendo parceiro de seus alunos, tendo consciência que não é detentor de todo conhecimento. No cenário atual da educação, é possível perceber que a aprendizagem pode acontecer em vários espaços, não se restringindo apenas a sala de aula. É preciso ensinar os alunos a serem questionadores, críticos e reflexivos para compreender a realidade e poder atuar nela.

Nessa proposta pedagógica, torna-se cada vez menor a utilização do quadro-negro, do livro-texto e do professor conteudista, enquanto aumenta a integração de novas tecnologias. Entendemos que este processo não se trata de substituir o livro pelo texto tecnológico, a fala do docente e os recursos 
tradicionais pelo fascínio das novas tecnologias. 0 professor deve se apropriar dessa tecnologia para se lançar a novos desafios e reflexões sobre sua pratica docente e o processo de construção do conhecimento por parte do aluno. Não se pode esquecer que os mais poderosos e autênticos recursos da aprendizagem continuam sendo o professor e o aluno que, conjunta e dialeticamente, poderão descobrir novos caminhos para a aquisição do saber.

\section{CONTRIBUIÇÕES INOVADORAS DAS TECNOLOGIAS DIGITAIS NA EJA: ANÁLISE DAS PUBLICAÇÕES DOS ANAIS DO ALFAEEJA}

$\mathrm{Na}$ perspectiva do uso das tecnologias nas classes do ensino da EJA observamos que há um conjunto de preocupações das instituições formadoras, como a UNEB, para fortalecer este processo formativo. Por isso, o universo de estudo desta pesquisa compreende os artigos publicados nos Anais do Encontro Internacional de Alfabetização e Educação de Jovens e Adultos (ALFAEEJA/ UNEB) desde sua primeira edição em 2014 até a edição de 2018. Deste universo foi analisada a amostra dos artigos que tratam do tema tecnologia digitais no campo da EJA publicados no eixo 3, 6 e 9 dos anais ao longo das edições do evento internacional.

De acordo com os documentos consultados no site do Encontro Internacional de Alfabetização e Educação de Jovens e Adultos (BAHIA, 2014-2018) as diferentes edições do evento são promovidas pelo Programa de Pós-Graduação em Educação de Jovens e Adultos (MPEJA) da Universidade Estadual da Bahia (UNEB) e contam com a participação de várias Instituições de Educação Superior (IES) do Brasil e de outros países.
Analisando o as informações oficiais do ALFAEEJA (2018, p. 2), divulgadas no site dos Encontros, observamos que o mesmo tem a intenção de promover o diálogo entre pesquisadores brasileiros e estrangeiros, para fortalecer os processos de alfabetização e da EJA, no atual cenário educacional brasileiro e internacional. Além disso, notamos que uma das marcas dos Encontros Internacionais é o de garantir a realização do diálogo permanente entre os participantes, para difundir e promover a discussão sobre a escolarização na EJA e refletir sobre os Programas Brasil Alfabetizado, Fórum de EJA e o TOPA. Há a intensão de envolver neste processo reflexivo, os estudantes de graduação e de Pós-Graduação em Educação e em EJA, estudantes de graduação em Pedagogia e das demais Licenciaturas, gestores e professores da rede pública e privada de ensino.

Para maior entendimento sobre a organização dos Encontros do ALFAEEJA ao longo das cinco edições já realizadas, partimos das informações constantes do site do Encontro Internacional de Alfabetização e Educação de Jovens e Adultos (2018) destacando que nos anos de 2014 e 2015, os Encontros aconteceram na cidade de Salvador. Em seguida, o III ALFAEEJA de 2016, já foi realizado na Universidade do Estado da Bahia, em Salvador e na Universidade Federal de Santa Catarina, em Florianópolis, ampliando o alcance nacional do mesmo.

Da mesma forma, observamos na apresentação do IV ALFAEEJA de 2017, que o mesmo também foi ampliado, obtendo o caráter de internacionalização, tendo a sua pré-abertura efetivada em Salvador. Depois, numa segunda etapa, o Encontro ocorreu na Universidade Federal de Santa Catarina, ganhando as dimensões da I Reunião Regional Sul, em Florianópolis. No mesmo período, ocorreu o processo de internacionalização, com a fina- 
lização do Encontro daquele ano, sendo efetivada nas Universidades do Minho e de Coimbra, em Portugal (BAHIA, 2014-2018).

Finalmente, pelo histórico das diferentes apresentações do Encontro Internacional de Alfabetização e Educação de Jovens e Adultos, analisado no site do mesmo, podemos afirmar que o V ALFAEJA teve a sua abertura sendo realizada em Salvador, e a complementação do Encontro sendo finalizada, na Universidade Federal do Rio Grande do Sul, em Porto Alegre

É válido ressaltarmos que a partir da quarta edição do ALFAEEJA, os Anais passaram a ser publicados separados, por cidade de realização do evento, porém seguindo os mesmos eixos temáticos. Logo, para revisão sistemática consideramos os Anais por ano de realização do evento, fazendo a junção destes quando publicados separados por cidade, já que em cada cidade foram apresentados trabalhos diferentes, o que enriquece nosso estudo.

Os trabalhos foram analisados a partir do levantamento dos Anais na página online do Encontro Internacional de Alfabetização e Educação de Jovens e Adultos. Os Anais foram organizados e publicados por eixos temáticos, assim com o uso das pala- vras-chave Tecnologia e Tecnologias digitais identificamos o eixo intitulado múltiplas linguagens, tecnologias da informação e da comunicação na EJA: perspectivas teóricometodológicas que nos serviu de fonte para a coleta dos dados.

Ressaltamos que nos eventos I e II ALFAEEJA, o eixo temático múltiplas linguagens, tecnologias da informação e da comunicação na EJA: perspectivas teórico-metodológicas se caracterizou como eixo 6. No III ALFAEEJA identificamos a temática no eixo 3 , sendo que os eventos do IV e V ALFAEEJA passou a ser eixo 9. Este eixo aborda o papel da escola na sistematização e diagnóstico das diferentes linguagens no processo de ensino - aprendizagem, levando em consideração as questões ambientais, culturais e tecnológicas, focando no uso das Tecnologia da Informação e Comunicação (TICs) na EJA e na Formação de professores.

Diante do exposto, consideramos importante que a equipe da organização mantenha os eixos na ordem que segue os anais do V ALFAEEJA nos demais eventos, favorecendo assim uma maior e melhor estruturação para pesquisadores que por ventura utilizarem os anais como fonte para obtenção de dados de pesquisa.

Quadro 1. Trabalhos publicados no eixo temático múltiplas linguagens, tecnologias da informação e da comunicação na EJA: perspectivas teórico-metodológicas

\begin{tabular}{|c|c|c|c|}
\hline Edição & Ano do Evento & Trabalhos publicados & $\begin{array}{c}\text { Trabalhos } \\
\text { selecionados }\end{array}$ \\
\hline I ALFAEEJA & 2014 & 14 & 3 \\
\hline II ALFAEEJA & 2015 & 16 & 10 \\
\hline III ALFAEEJA & 2016 & 22 & 3 \\
\hline IV ALFAEEJA & 2017 & 21 & 21 \\
\hline V ALFAEEJA & 2018 & 31 & 24 \\
\hline \multicolumn{2}{|c|}{ TOTAL } & $\mathbf{1 0 4}$ & $\mathbf{6 1}$ \\
\hline
\end{tabular}

Fonte: Elaboração pelos pesquisadores, em 2019, a partir dos sites oficiais dos Encontros².

2 Informações de domínio público, cujos eventos foram financiados com recursos financeiros do Programa de Apoio a Eventos no País (PAEP) da Coordenação de Aperfeiçoamento de Pessoal de Nível Superior (CAPES) nos anos de 2015, 2016, 2017 e 2018, sendo captados pelo MPEJA/UNEB e pelo Programa de Pós-Graduação em Educação (PPGE) da UFSC, em 2016 e pela Fundação de Amparo à Pesquisa de Santa Catarina (FAPESC), em 2017. 
O Quadro 1 apresenta algumas informações sobre os trabalhos publicados no eixo temático supracitado ao longo das cinco edições do evento e as publicações selecionadas para a análise com base nas palavraschaves tecnologias, tecnologias digitais, TIC, TICS, aplicativos e digital.

De 2014 a 2018 foram publicados 104 trabalhos no eixo temático que envolve tecnologias da informação e da comunicação na EJA. Com o uso das palavras-chave tecnologias, tecnologias digitais, TIC, TICS, aplicativos e digital realizamos uma observação sistemática nos títulos das publicações e identificamos 61 trabalhos que envolvem a temática de nosso interesse de estudo.

Nessa perspectiva, notamos que 43 dos trabalhos publicados no eixo não versavam especificamente em tecnologias digitais, esses trabalhos foram excluídos da nossa investigação, pois nosso objetivo é investigar a inserção das tecnologias digitais na EJA. Notamos que entre os trabalhos selecionados a partir das palavras-chave tecnologias, tecnologias digitais, TIC, TICS, aplicativos e digital houve uma oscilação na quantidade de trabalhos publicados ao longo das edições. Percebemos também que do primeiro para o quinto evento o número de trabalhos publicados sobre tecnologias digitais aumentou consideravelmente. Isso reforça que o ALFAEEJA vem impulsionando a realização de pesquisas sobre tecnologias digitais no campo da educação de jovens e adultos o que mostra o papel da universidade em manter um diálogo contínuo com sua comunidade, subsidiando novos saberes e fazeres mediados pelas tecnologias (ALVES, 2016).

É válido ressaltar que o evento recebe submissões de trabalhos de vários estados do Brasil, contudo o estudo em questão, após realizados os filtros para a escolha e posterior análise dos artigos, selecionou 5 trabalhos, sendo quatro de mestrandos do Programa de Pós-Graduação em Educação de Jovens e Adultos e um de um professor tutor do Serviço Social da Indústria (SESI).

Ao analisarmos os trabalhos selecionados a partir dos títulos, resumos e palavras chaves verificamos que existe um foco nas tecnologias seguindo certa ordem temporal do avanço dessas tecnologias em cada ano de publicação. Iniciando com trabalhos que envolviam o computador, internet, redes sociais até os dispositivos móveis. Assim, optamos por analisar integralmente um trabalho em cada edição do evento, selecionamos cinco trabalhos de destaque, conforme apresentados no Quadro 2. A maioria dos demais trabalhos tinham abordagens com temáticas parecidas, por isso os excluímos dessa seleção.

Quadro 2. Trabalhos selecionados para análise.

\begin{tabular}{|l|c|l|l|}
\hline \multicolumn{1}{|c|}{ Edição } & Ano do Evento & \multicolumn{1}{|c|}{ Título do trabalho } & \multicolumn{1}{c|}{ Autor (es) } \\
\hline ALFAEEJA I & 2014 & $\begin{array}{l}\text { As TIC digitais como caminhos didáticos: } \\
\text { uma avaliação da oficina de informática } \\
\text { para EJA. }\end{array}$ & Amilton Alves de Souza \\
\hline $\begin{array}{l}\text { ALFAEEJA } \\
\text { II }\end{array}$ & 2015 & $\begin{array}{l}\text { Construindo uma aprendizagem } \\
\text { significativa em matemática pela } \\
\text { mediação dos dispositivos móveis e } \\
\text { seus aplicativos na educação de jovens e } \\
\text { adultos }\end{array}$ & Eduardo Brito Correia \\
\hline $\begin{array}{l}\text { ALFAEEJA } \\
\text { III }\end{array}$ & 2016 & $\begin{array}{l}\text { Práticas de letramento na EJA em } \\
\text { aplicativo de comunicação }\end{array}$ & $\begin{array}{l}\text { Gilberto Pereira } \\
\text { Fernandes e Maria Olivia } \\
\text { de Matos Oliveira }\end{array}$ \\
\hline
\end{tabular}




\begin{tabular}{|l|l|l|l|}
\hline $\begin{array}{l}\text { ALFAEEJA } \\
\text { IV }\end{array}$ & 2017 & $\begin{array}{l}\text { As TIC no contexto formativo da EJA: um } \\
\text { olhar reflexivo sobre a vida escolar em } \\
\text { redes sociais de estudantes do proeja }\end{array}$ & Jailson Silva Lima \\
\hline $\begin{array}{l}\text { ALFAEEJA } \\
\text { V }\end{array}$ & 2018 & $\begin{array}{l}\text { Gamificação como instrumento de } \\
\text { avaliação na EJA EAD. }\end{array}$ & Danilo Bastos Cunha \\
\hline
\end{tabular}

Fonte: Elaboração pelos pesquisadores, em 2019, a partir dos sites oficiais dos Encontros.

Por isso, podemos analisar o trabalho a partir do I ALFAEEJA, o trabalho que tem como título: As TIC digitais como caminhos didáticos: uma avaliação da oficina de informática para EJA, autoria de Souza (2014), teve por objetivo apresentar a trajetória do uso das Tecnologias da Informação e Comunicação a partir da avaliação da Oficina de Informática para EJA. 0 autor realizou uma pesquisa documental a fim de analisar se o uso das Tecnologias da Informação e Comunicação como caminhos didáticos por meio do "Projeto Oficina de Informática, articulado com a Leitura e Escrita" tem contribuído ou não para melhoria do ensino e da aprendizagem na Escola Municipal Miguel Santos Fontes - Araçás/BA nas turmas do ensino médio.

Nessa perspectiva, Souza (2014) apresenta as tecnologias da informação e comunicação na perspectiva do digital, ressaltando o uso do computador como ferramenta para a melhoria do ensino e da aprendizagem dos sujeitos da EJA no que tange leitura e escrita. Segundo o autor, as oficinas eram realizadas visando o letramento dos sujeitos jovens e adultos por meio do hipertexto.

Desta forma, notamos que a proposta buscou a realização de um trabalho que superava o viés meramente instrumental da tecnologia, visando a inserção do computador como meio favorecedor de uma prática letrada e também multiletrada, considerando a realidade da colaboração nos espaços digitais. Segundo Alves (2016, p. 581);
[...] não basta ensinar aos alunos a usar essas tecnologias, evidenciando uma prática instrumental. 0 diferencial surge mediante a construção de práticas de atribuição de sentidos que valorizem a autonomia e a autoria dos sujeitos aprendentes, aproximando-se dos seus desejos e demandas, para resgatar o prazer de aprender no universo da escola.

Nesse âmbito, o artigo de Correia (2015) vem corroborar com a reflexão anterior quando em seu trabalho objetivou contribuir com as discussões acerca do uso dos dispositivos móveis na educação de jovens e adultos. Levando em consideração a aprendizagem significava na disciplina de Matemática, o autor apresentou uma experiência com a inserção do celular em suas aulas. A partir dessa experiência Correia ressaltou que os educandos se envolveram na pesquisa com o apoio do celular e realizaram comparações dos achados durante a pesquisa e das notícias veiculadas nos meios de comunicação de massa. Assim, notamos que o celular é uma tecnologia que quando bem utilizada oferece muitas ferramentas pedagógicas. Conforme Lemos (2010) o telefone celular tem sido o dispositivo maior da convergência tecnológica e também de constituição de relações sociais por contato imediato, seja por meio de voz, SMS, fotos ou vídeos.

A tecnologia móvel como o celular é uma possibilidade inovadora para se trabalhar na educação, contudo é necessária que o professor tenha conhecimento dessa ferramenta e que a escola disponha de redes $\mathrm{Wi}$ - 
Fi para acesso à internet que viabilize outras possibilidades interativas na construção do conhecimento.

Fernandes e Oliveira (2016) em Práticas de letramento na EJA em aplicativo de comunicação tiveram por objetivo entender como os professores veem os processos de letramento diante das novas tecnologias digitais e analisar práticas textuais digitais de letramento desses sujeitos da EJA em aplicativo de comunicação. Os sujeitos que fizeram parte da pesquisa foram os professores os quais por meio de um grupo no whatsapp dialogaram acerca de questões pertinentes ao letramento com as tecnologias digitais na EJA. Segundo os autores que acompanharam a participação dos professores no grupo, estes demonstraram inicialmente receio na utilização do aplicativo, mas com as discussões começaram a entender que aplicativos online podem servir como ferramenta educacional nos processos de letramento na Educação de Jovens e Adultos.

Para Rojo (2012), a multiplicidade de linguagens (imagens, sons, links, vídeos, cores) dos textos contemporâneos, tanto em ambientes digitais quanto impressos requer capacidade crítica para compreende-los. Assim, notamos uma necessidade em trabalharmos na perspectiva do letramento digital que vá além do simples manuseio do computador ou celular para a realização de pesquisa, estes sujeitos precisam se apropriar de como identificar, selecionar, avaliar e utilizar as informações de forma crítica para a construção do conhecimento.

0 trabalho as TIC no contexto formativo da EJA: um olhar reflexivo sobre a vida escolar em redes sociais de estudantes do PROEJA autoria de Lima (2017) foi resultado da pesquisa de dissertação do referido autor e objetivou compreender as itinerâncias formativas, escolares e profissionais dos estu- dantes do PROEJA, identificando os valores, significados e as experiências de aprendizagem atribuídos à aquisição e aos usos das TIC, na perspectiva de contribuir com a melhoria da educação profissional no Estado da Bahia.

Lima (2017) desenvolveu uma pesquisa de natureza aplicada e de abordagem participante. Como produto da pesquisa ele sinaliza a criação de ações pedagógicas e tecnológicas em ambientes formativos que resultem em aprendizagem significativa através da interatividade, proporcionada pelas interfaces comunicacionais do BLOG. Por ser um resumo da sua dissertação, o trabalho publicado nos anais do IV ALFAEEJA não deixa clara como foi a participação dos alunos da EJA no Blog. Isso dificultou uma análise mais detalhada de como o Blog foi trabalhado com os sujeitos da EJA e quais os resultados obtidos. Com base no título do trabalho esperávamos uma proposta que analisasse de forma mais aprofundada as redes sociais no contexto da educação de jovens e adultos.

Assim, consideramos importante a realização de pesquisas sobre as redes sociais no contexto da educação de jovens e adultos. Essas redes se configuram como uma necessidade na sociedade contemporânea já que está se encontra cada vez mais informatizada, as pessoas estão mais conectadas e se dirigindo aos ciberespaços. Desta forma, acreditamos que os sujeitos da EJA também estejam nesse espaço e precisam ter uma formação que os torne mais autônomos e críticos para atuarem como cidadãos nesses espaços.

O trabalho de Cunha (2018), intitulado Gamificação como instrumento de avaliação na EJA, na modalidade EAD apresentado no $\mathrm{V}$ ALFAEEJA objetivou proporcionar uma reflexão sobre o uso das Metodologias Ati- 
vas de Ensino (MAE), e de Software, como método de avaliação no processo de ensino da Matemática. Assim, com a finalidade de avaliar o conhecimento matemático dos alunos, o autor elaborou um projeto, onde fez uma junção das metodologias ativas Team Based Learning, Problem Based Learning e a Gamificação.

Conforme Cunha (2018), a utilização das metodologias ativas supracitadas visou problematizar as habilidades e competências matemáticas dos alunos e a valorização dos seus conhecimentos prévios. Nesse processo, a gamificação teve o papel de suavizar a aula de Matemática, possibilitando ao aluno uma aprendizagem mais descontraída, utilizando a plataforma Kahoot.

Segundo o autor, o estudo mostrou que é possível avaliar os alunos mesmo sem discutir os conteúdos, de maneira tradicional, pois eles conseguiriam pensar de maneira lógica e utilizar seus saberes adquiridos no decorrer de sua vida, para resolver as questões geradoras que estavam de acordo com os métodos institucionalizados. Houve interação entre os alunos, valorização de seus conhecimentos prévios, e ao mesmo tempo, tornou-se mais divertido aprender Matemática.

Frente a essa proposta de inserção de metodologias ativas como a gamificação na educação de jovens e adultos, notamos que é possível e necessário criarmos ambientes educacionais, que sejam mais interativos e em consonância com a era digital na qual vivemos, para possibilitar aos sujeitos da EJA potencializarem as suas aprendizagens. Assim, "[...] construir um sentido diferenciado para as tecnologias digitais e da web nos espaços escolares requer uma mudança de papel dos professores e dos alunos, permitindo que sejam atores e autores das suas trajetórias de aprendizagem" (ALVES, 2016, p. 577).
Diante do exposto, os trabalhos analisados corroboram de forma significativa para o campo da Educação de Jovens e Adultos, pois, apresentam propostas que inserem as tecnologias digitais no processo de ensino -aprendizagem, evidenciando uma superação do viés meramente instrumental. Isso torna-se perceptível nas produções quando os pesquisadores buscam trabalhar os recursos tecnológicos visando a autonomia e a formação crítica dos alunos. É por isso que Alves (2016) afirma que os professores e os alunos devem vivenciar situações que favoreçam essa autonomia.

Outro ponto que chama a atenção é que quatro dos cinco trabalhos aqui analisados são de alunos do Programa de Pós-Graduação em Educação de Jovens e Adultos da Universidade do Estado da Bahia. Assim, acreditamos que o MPEJA vem contribuindo de forma significativa para a pesquisa no âmbito da EJA, a nível internacional, considerando a qualidade dos trabalhos apresentados.

Frente ao exposto, sabemos que utilizar as tecnologias como sendo recurso pedagógico nas instituições educacionais, já não é uma novidade. Analisando o impacto que as TICs exercem sobre o processo de ensino-aprendizagem, exige-se que a educação seja repensada e que o sistema educacional possa dar condições para que os professores possam desfrutar deste recurso da melhor maneira possível. Se o educador não souber utilizar essa tecnologia de maneira criativa, dificilmente, ele conseguiria desenvolver um trabalho que despertasse no educando o prazer pelo conhecimento. É preciso compreender que, para a tecnologia contribuir com o processo de construção da aprendizagem, é necessário que o professor tenha uma proposta que alcance os interesses e os objetivos dos seus alunos e que estes se 
sintam motivados e atraídos pelo que está sendo proposto.

É necessário que aconteçam mudanças nos currículos tradicionais e nas práticas escolares para acompanhar os avanços provocados pela tecnologia no cotidiano dos alunos. E a integração dessas tecnologias ao currículo é de fundamental importância para que essas mudanças aconteçam definitivamente. Os alunos da EJA fazem parte da sociedade da informação e levam a tecnologia para todos os espaços, dentro e fora da escola, o que possibilita a expansão dos processos de ensino e aprendizagem. Assim, Brito e Purificação (2006, p. 31) afirmam que:

A tecnologia educacional, sabiamente, não se reduz à utilização de meios. Ela precisa necessariamente ser um instrumento mediador entre o homem e o mundo, o homem e a educação, servindo de mecanismo pelo qual o educando se apropria de um saber, redescobrindo e reconstruindo o conhecimento.

É importante ainda ressaltar que um dos fatores que modificam o modo como jovens e adultos apreendem, tem a ver diretamente com o conhecimento de que já dispõem: aquele que foi adquirido com as experiências fora do ambiente escolar. A família e a comunidade são ambientes muito propensos à aprendizagem, nem sempre de assuntos do currículo formal escolar, mas de experiências que corroboram com o desenvolvimento de outras habilidades ao sujeito.

\section{CONSIDERAÇÕES FINAIS}

Chegamos ao final desta investigação, acreditando na integração das tecnologias digitais como meio que pode favorecer uma prática pedagógica alicerçada na práxis e na construção do conhecimento, pois, vivenciamos uma era onde essas tecnologias estão diariamente presentes na vida das pessoas, fazendo-se necessário estar também nas escolas, aliás, a escola tem que ser um dos principais meios de acesso a essas tecnologias, favorecendo uma formação mais consciente, reflexiva, e geradora de ganhos significativos para o aprendizado.

Defendemos que ainda há uma trilha a ser percorrida a qual passa pela formação dos professores, os quais precisam emergir nos âmbitos que entrelaçam a presença das tecnologias na sociedade contemporânea e buscar principalmente nas universidades espaço para continuarem se formando. Utilizar as tecnologias digitais como dispositivo pedagógico nas instituições educacionais já não é novidade, contudo pensar a inserção dessas tecnologias na Educação de Jovens e Adultos se constutui urgente visto a ausência de projetos na EJA que envolvam inovação e que considerem os sujeitos como cidadãos ativos na sociedade da informação.

No entanto, vimos que para inovar na Educação de Jovens e Adultos precisamos conhecer seu contexto histórico, considerar suas especificidades e lutar em busca de sua valorização enquanto política publica de direito para os sujeitos que dela fazem parte. Neste âmbito, este estudo demostrou que as tecnologias digitais estão sendo inseridas na educação de jovens e adultos, de forma tímida, sendo que ainda são poucas as experiências nesta área. É válido ressaltar que as propostas aqui apresentadas superam o viés instrumental do uso das tecnologias, pois, buscam inseri-las na formação dos sujeitos jovens e adultos visando a reconstrução de seu papel na sociedade.

Neste sentido, ficou notório que as tecnologias digitais estão cada dia mais presentes na vida das pessoas, e a escola não pode negar essa existência, ela deve trazer essa realidade para o seu currículo. Os professores 
precisam estar atentos a esses processos, buscando fomentar seus conhecimentos a partir da pesquisa e de uma formação continuada na área. A todo o momento surgem novos aparatos e interfaces tecnológicas e a escola precisa acompanhar essas inovações, pesquisando o potencial educativo dessas ferramentas e como os alunos as utilizam. Descobrir quem são nossos alunos, quais as tecnologias que utilizam e como podemos integra-las ao contexto educativo são ações necessárias ao processo de ensino-aprendizagem significativo.

Consideramos também a importância das diferentes edições do Encontro Internacional de Alfabetização e Educação de Jovens e Adultos (ALFAEEJA) para o reconhecimento e a valorização da EJA, fazendo parte da luta para que se torne uma política pública de Estado. A EJA enquanto direito deve formar os sujeitos ao longo da vida, e isso envolve mais do que ensinar os conteúdos legalmente instituídos. Concluímos destacando que muitos paradigmas e preconceitos precisam ser superados para a inserção eficaz das tecnologias digitais na escola da EJA.

\section{REFERÊNCIAS}

ALVES, Lynn. Práticas inventivas na interação com as tecnologias digitais e telemáticas: o caso do Gamebook Guardiões da Floresta. R. Educ. Públ. Cuiabá. v. 25. n. 59/2.p. 574-593. maio/ ago. 2016.

ALVES, Lynn. Práticas inventivas na interação com as tecnologias digitais e telemáticas: o caso do Gamebook Guardiões da Floresta. R. Educ. Públ. Cuiabá. v. 25. n. 59/2.p. 574-593. maio/ ago. 2016.

ALVES, Lynn. Práticas inventivas na interação com as tecnologias digitais e telemáticas: o caso do Gamebook Guardiões da Floresta. R. Educ. Públ. Cuiabá. v. 25. n. 59/2.p. 574-593. maio/ ago. 2016.
ARROYO, Miguel González. Educação de jovens -adultos: um campo de direitos e de responsabilidade pública. In: SOARES, Leôncio; GIOVANETTI, Maria Amélia G. C.; GOMES, Nilma Lino (orgs.). Diálogos na educação de jovens e adultos. Belo Horizonte: Autêntica, 2005. p. 1950 .

ARROYO, Miguel González. Educação de jovens -adultos: um campo de direitos e de responsabilidade pública. In: SOARES, Leôncio; GIOVANETTI, Maria Amélia G. C.; GOMES, Nilma Lino (orgs.). Diálogos na educação de jovens e adultos. Belo Horizonte: Autêntica, 2005. p. 19- 50.

BAHIA. Universidade do Estado da Bahia. Programa de Pós-Graduação em Educação de Jovens e Adultos (MPEJA). Apresentações e dados dos Encontros Internacionais de Alfabetização e Educação de Jovens e Adultos de 2014 a 2018. Salvador: UNEB, 2018. Disponível em: Página eletrônica. Salvador: UNEB, 2014-2018. Disponível em: <https://www.alfaeejauneb.com>. Acesso em 22 nov. 2018.

BAHIA. Universidade do Estado da Bahia. Programa de Pós-Graduação em Educação de Jovens e Adultos (MPEJA). Anais eletrônicos. Salvador: UNEB, 2018. Disponível em: Anais do Encontro Internacional de Alfabetização e Educação de Jovens e Adultos Anais eletrônicos. Salvador: UNEB, 2014-2018a. Disponível em: <https://www.alfaeejauneb.com>. Acesso em 22 nov. 2018.

BRASIL. Congresso Nacional. Lei de Diretrizes e Bases da Educação Nacional - Lei 9.394/96, de 20 de dezembro de 1996. Diário da União, p. 35-36, de 23 de dezembro de 1996.

BRITO, Gláucia da Silva; PURIFICAÇÃO, Ivonélia da. Educação e novas tecnologias: um repensar. Curitiba: IBPEX, 2006.

CORREIA, Eduardo Brito. Construindo uma aprendizagem significativa em Matemática pela mediação dos dispositivos móveis e seus aplicativos na educação de jovens e adultos. In: II Encontro Internacional de Alfabetização e Educação de Jovens e Adultos. Eixo 6, , Salvador. Anais... Salvador: ALFAEEJA, 2015. Disponível em: <https://www.alfaeejauneb.com>. Acesso em 22 nov. 2018.

COSTA, Cláudia Borges. MACHADO, Maria Margarida. Políticas públicas e Educação de Jo- 
vens e Adultos no Brasil. 1. ed. São Paulo: Cortez, 2017.

CRESWELL, J. W. Projeto de pesquisa: métodos qualitativo, quantitativo e misto. Porto Alegre: Artmed, 2007.

CUNHA, Danilo Bastos. Gamificação como instrumento de avaliação na EJA ead. In: V Encontro Internacional de Alfabetização e Educação de Jovens e Adultos. Eixo 9. 2018. Salvador. Anais... Salvador: ALFAEEJA, 2018. Disponível em: <https://www.alfaeejauneb.com>. Acesso em 22 nov. 2018.

FARIA, Edite Maria da Silva. A precarização e a (des)profissionalização docente na educação de jovens e adultos trabalhadores. In: VIII Seminário do Trabalho, Trabalho e Educação e Políticas Sociais no século XXI - GT7 - trabalho, tecnologia e reestruturação produtiva. Anais... Marília, SP: UNESP, 2012. Disponível em: < http://www. estudosdotrabalho.org/texto/gt7/a_precarizacao.pdf> Acesso em: 02 set. 2018.

FERNANDES, Gilberto Pereira. OLIVEIRA, Maria Olivia de Matos. Práticas de letramento na EJA em aplicativo de comunicação. In: III Encontro Internacional de Alfabetização e Educação de Jovens e Adultos. Eixo 3. 2016. Florianópolis. Anais... Florianópolis: ALFAeEJA, 2016. Disponível em: <https://www.alfaeejauneb.com>. Acesso em 22 nov. 2018.

GIL, Antônio Carlos. Como elaborar projetos de pesquisa. 4. ed. São Paulo: Atlas, 2002.

Métodos e técnicas de pesquisa social. 6. ed. São Paulo: Atlas, 2008.

LEMOS, André. Celulares, funções pós-midiáticas, cidade e mobilidade. Urbe. Revista Brasileira de Gestão Urbana (Brazilian Journal of Urban Management), v. 2, n. 2, p. 155-166, jul./ dez. 2010.
LÉVY, Pierre. Cibercultura. São Paulo: Ed. 34, 1999.

LIMA, Jailson Silva. As TIC no contexto formativo da EJA: um olhar reflexivo sobre a vida escolar em redes sociais de estudantes do PROEJA. In: IV Encontro Internacional de Alfabetização e Educação de Jovens e Adultos - Eixo 9., Florianópolis. Anais... Florianópolis: ALFAeEJA, 2016. Disponível em: <https://www.alfaeejauneb. com>. Acesso em 22 nov. 2018.

ROJO, R.; MOURA, E. (Org.). Multiletramentos na escola. São Paulo: Parábola, 2012.

SAMPAIO, R. F. MANCINI, M. C. Estudos de Revisão Sistemática: um guia para síntese criteriosa da evidência científica. Revista Brasileira de Fisioterapia, São Carlos, v.11, n. 1, p. 83-89, jan./fev. 2007.

\section{SEVERINO, A. J. Metodologia do trabalho cien-} tífico. São Paulo: Cortez, 2007.

SILVEIRA, Denise Tolfo. CÓRDOVA, Fernanda Peixoto. A pesquisa científica. In: GERHARDT, Tatiana Engel. SILVEIRA, Denise Tolfo. (Org). Coordenado pela Universidade Aberta do Brasil - UAB/UFRGS e pelo Curso de Graduação Tecnológica - Planejamento e Gestão para o Desenvolvimento Rural da SEAD/UFRGS. Métodos de pesquisa. Porto Alegre: Editora da UFRGS, 2009.

SOUZA, Amilton Alves de. As TIC digitais como caminhos didáticos: uma avaliação da oficina de informática para EJA. In: I Encontro Internacional de Alfabetização e Educação de Jovens e Adultos. Eixo 6. Salvador. Anais... Salvador: ALFAEEJA, 2014. Disponível em: Disponível em: <https://www.alfaeejauneb.com>. Acesso em 22 nov. 2018. 